\title{
Geochemical characteristics of bauxite-associated high lithium claystone in western Guangxi, China
}

J.Q. XU ${ }^{1}$, B.C. PANG ${ }^{1 *}$, G.H. LU ${ }^{2}$, Z.L. LI ${ }^{1}$, H.P. XU ${ }^{2}$, D.B. LIANG ${ }^{1}$, J.W. LUO ${ }^{1}$, Y.Q. ZHOU ${ }^{2}$ AND Y.B. ZHOU ${ }^{2}$

${ }^{1}$ Guilin University of Technology, Guilin 541006, China (jianqi_xu@126.com, *correspondence: pbc@glut.edu.cn)

${ }^{2}$ The Guangxi Zhuang Autonomous Region 274 geological team, Beihai 536005, China

Lithium is a kind of critical metals, which is crucial to the development of strategic emerging industries [1, 2]. The preliminary analysis shows that lithium is distinctly concentrated in the claystone that associated with karst bauxite, including low-aluminum bauxite, carbonaceous shale and carbonaceous mudstone, in western Guangxi. Of 40 samples, the contents of $\mathrm{Li}_{2} \mathrm{O}$ in 21 samples are over $0.1 \%$, and the highest one is up to $0.54 \%$.

The enrichment of lithium in these claystones may be related to sedimentary environment, and geochemical method is an important approach to analyze it. Previous researches have shown that some trace elements are vital indicators for sedimentary environment, including paleosalinity, $\mathrm{pH}$ value, oxdation and reduction [3, 4]. The data of 19 analyzed samples shows that the values of $\omega(\mathrm{Sr}) / \omega(\mathrm{Ba})$ in most of samples are more than 1.0, with an average of 1.26. $\omega(\mathrm{V}) / \omega(\mathrm{Zr})$ range from 0.16 to $0.79,0.26$ on average. These two indicators tell that bauxite-associated claystone might be deposited in marine or transitional facies. The values of $\omega(\mathrm{La}) / \omega(\mathrm{Y})$ range from 0.58 to 2.49 , with an average of 1.21 , which indicate that alkaline environment accounts for lithium-contained claystone depositing. Reductive or subreductive environment is revealed by the values of $\omega(\mathrm{Y}) / \omega(\mathrm{Ho})$ and $\omega(\mathrm{V}) / \omega(\mathrm{V}+\mathrm{Ni})$. The values of $\omega(\mathrm{Y}) / \omega(\mathrm{Ho})$ of all samples are less than 44 , and the values of $\omega(\mathrm{V}) / \omega(\mathrm{V}+\mathrm{Ni})$ range from 0.67 to 1.00 , which prove that these claystones were formed in oxygen-deficient environment.

Based on analysis above, it can be concluded that bauxiteassociated high lithium claystone in western Guangxi was formed in alkaline, reductive or subreductive marine environment.

Acknowledgements: This research is supported by the National Natural Science Foundation of China (41362006).

[1] Schulz et al. (2017) Virginia: US Geological Survey, 797. [2] Wen et al. (2020) China Sci Bull 65, 53-59. [3] Cui et al. (2013) Geol. Sci. \& Tech. Info. 32, 46-51. [4] Wang et al.

(2017) Acta Sedimentologica Sinica 35, 1265-1273. 